\title{
Rate of over-diagnosis of breast cancer 15 years after end of Malmö mammographic screening trial: follow-up study
}

\author{
Sophia Zackrisson, Ingvar Andersson, Lars Janzon, Jonas Manjer, Jens Peter Garne
}

\begin{abstract}
Objective To evaluate the rate of over-diagnosis of breast cancer 15 years after the end of the Malmö mammographic screening trial.

Design Follow-up study.

Setting Malmö, Sweden.

Subjects 42283 women aged 45-69 years at randomisation. Interventions Screening for breast cancer with mammography or not (controls). Screening was offered at the end of the randomisation design to both groups aged 45-54 at randomisation but not to groups aged 55-69 at randomisation. Main outcome measures Rate of over-diagnosis of breast cancer (in situ and invasive), calculated as incidence in the invited and control groups, during period of randomised design (period 1), during period after randomised design ended (period 2), and at end of follow-up.

Results In women aged 55-69 years at randomisation the relative rates of over-diagnosis of breast cancer (95\% confidence intervals) were 1.32 (1.14 to 1.53 ) for period $1,0.92$ (0.79 to 1.06 ) for period 2, and 1.10 (0.99 to 1.22$)$ at the end of follow-up.

Conclusion Conclusions on over-diagnosis of breast cancer in the Malmö mammographic screening trial can be drawn mainly for women aged 55-69 years at randomisation whose control groups were never screened. Fifteen years after the trial ended the rate of over-diagnosis of breast cancer was $10 \%$ in this age group.
\end{abstract}

\section{Introduction}

Over-diagnosis of breast cancer at screening may be defined as the detection of cases that would never have come to clinical attention without screening. ${ }^{1-3}$ The rate of this negative side effect of screening has been estimated at $5-50 \%$. $^{4-7}$

The most feasible means of assessing over-diagnosis would be to study the cumulative incidence of breast cancer over time in women invited to screening compared with unscreened controls. ${ }^{8}$ The Malmö mammographic screening trial can provide such data. ${ }^{9}$ This trial was unique in being a population based trial, with randomisation by individual. The trial period ended after 10 years and at that time 141 more cases of breast cancer were detected in the invited group than in the control group. In the 15 oldest birth cohorts, born 1908-22 (aged 55-69 at entry to the study), the control groups were never invited to screening, whereas in the 10 youngest birth cohorts, born 1923-32 (aged 45-54 at entry to the study), the control groups were eventually invited. This provides an opportunity to study changes in the excess number of cases of breast cancer in the invited group over time.

When screening of the invited group stops the incidence of breast cancer should decrease over time, the duration of which depends on the distribution of lead times (time from actual detection to the supposed clinical appearance in the absence of screening) of the tumours detected at screening. When the control group is invited, the excess number of cases in the invited group would over time be balanced by an equal number of cases in the control group. The validity of this assumption can be evaluated within the context of the Malmö trial.

We evaluated the rate of over-diagnosis of breast cancer in the Malmö mammographic screening trial 15 years after the trial ended by comparing the incidence of in situ and invasive cancers in the invited groups and unscreened control groups. We also show the changes in incidence when control groups were invited for screening after randomisation.

\section{Methods}

In the Malmö mammographic screening trial all women born during 1908-32 and living in Malmö were randomly allocated to invitation to screening with mammography or no screening (controls). The study started in October 1976 and women were invited by letter. The cohort comprised 42283 women: 21088 were allocated to the invited group and 21195 to the control group. Each birth year cohort was randomised separately from the start of the trial to 1978, and the first screening round was completed by the end of 1978 . The screening interval was 18 to 24 months. The trial ended in December 1986 and was reported in $1988 .^{9}$

We followed the cohorts from the date of randomisation until 31 December 2001, 15 years after the trial ended. Survival and detection of breast cancer for each woman was obtained by record linkage with the Swedish Cancer Registry and the Swedish Causes of Death Registry. We only included a first time diagnosis of breast cancer during follow-up. A total of 2525 cases of breast cancer were registered during the study period, 1320 in invited women and 1205 in controls. Invasive breast cancer constituted $91 \%(n=1200)$ of the cases in the invited group and 93\% $(\mathrm{n}=1116)$ in the control group.

The evaluation of the incidence of breast cancer in both groups is based on two time periods. Figure 1 gives a schematic overview of the periods and the screening status for the birth cohorts (see bmj.com for detailed description of periods). Period

Detailed description of time periods is on bmj.com 


\section{Research}

1 comprises the phase when the randomised design was maintained, which for women born during 1908-17 equalled the trial time, for women born during 1918-22 the trial time and the years after the trial up to age 70 , and for women born during 1923-32 the trial time and the years after until invitation of the control groups began in 1990. Period 2 refers to the phase after the randomised design ended until the end of follow-up in 2001. In older women (born 1908-22) period 2 implied the end of screening in the invited group and no invitation of the control group. Only the youngest age groups (born 1923-32) were offered screening, in both the invited and the control groups. The timing of invitation of the control groups ranged from September 1990 until February 1993. The screening interval was 18-24 months from 1990 onwards, depending on age and parenchymal pattern of breast tissue. The incidence refers to the total incidence-that is, cancers detected at screening, in the intervals between screenings, among non-attenders, and in the control group

\section{Statistical analysis}

We calculated the incidence of breast cancer, invasive and in situ, in the total study cohort (women born 1908-32) for the invited group and the control group for the total period of follow-up (periods 1 and 2) and separately for periods 1 and 2. This was repeated for two subgroups on the basis of exposure to screening in period 2: women born during 1908-22 (aged 55-69 at randomisation) and those born during 1923-32 (aged 45-54 at randomisation). We used Cox's proportional hazards analysis to estimate relative rates with 95\% confidence intervals of breast cancer in the invited groups compared with the control groups. The analysis was repeated for the total follow-up, including only invasive breast cancer.

To compare incidence rates without a majority of prevalent cases, we compared the incidence in period 1 after the exclusion of breast cancer cases in the time period corresponding to the first two screening rounds. The first two rounds were excluded to be able to include non-attenders in the first round who attended the second round and had a cancer detected. SPSS 11.0 for Windows was used for all calculations.

\section{Results}

Over-diagnosis can be illustrated in the Malmö mammographic screening trial as the cumulative number of breast cancers in the group invited for screening and the control group for the total follow-up. A clear difference in the cumulative number of all cases of breast cancer (invasive and in situ) is seen in the invited and control groups in women born 1908-22, when screening of

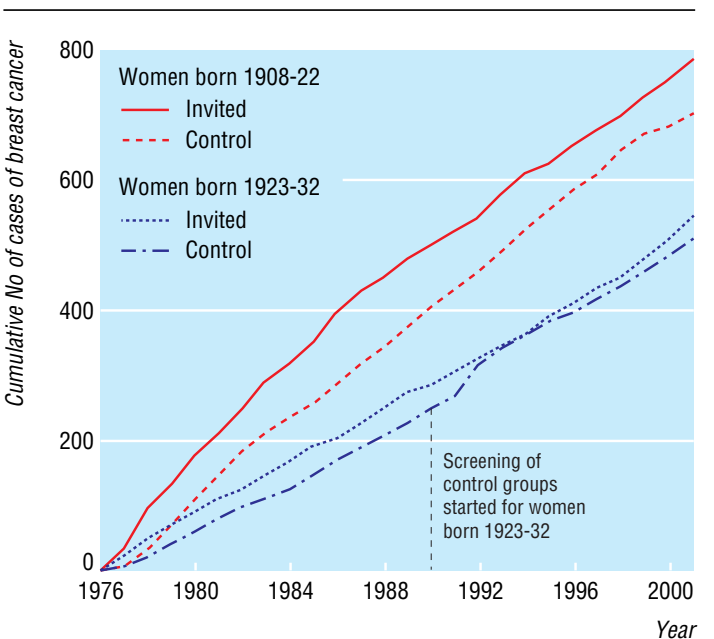

Fig 2 Cumulative number of all breast cancer cases (in situ and invasive) per year and group for total follow-up of women born during 1908-22 (unscreened control group) and 1923-32 (controls groups invited to screening from 1990 onwards)

the control group never occurred (fig 2). The curves separate immediately and continue to widen for several years. A difference remains during the whole of follow-up. The curves converged when screening stopped. In women born during 1923-32, the curves separate immediately but converge when the control groups were invited from 1990 onwards, reflecting the prevalence screening. A small difference re-emerges between the groups at the end of follow-up.

When over-diagnosis was expressed as a rate, the following was noted. Fifteen years after the trial ended the invited group showed a $10 \%$ significantly higher incidence of breast cancer (table 1). When cancer in situ was excluded, the incidence was $7 \%$ higher. Despite differences in exposure to screening, the older and the younger women had similar relative rates of over-diagnosis $(10 \%$ and $8 \%)$.

\section{Incidence during periods 1 and 2}

During period 1 the incidence of breast cancer was 24\% higher in the invited group than in the control group (table 2). During period 2, the incidence was $5 \%$ lower in the invited group than in the control group.

Women in the invited group who were aged 45-54 at randomisation had a $16 \%$ higher rate of breast cancer than the control group (table 2). Incidence did not differ during period 2, when both the invited and the control groups were screened. In

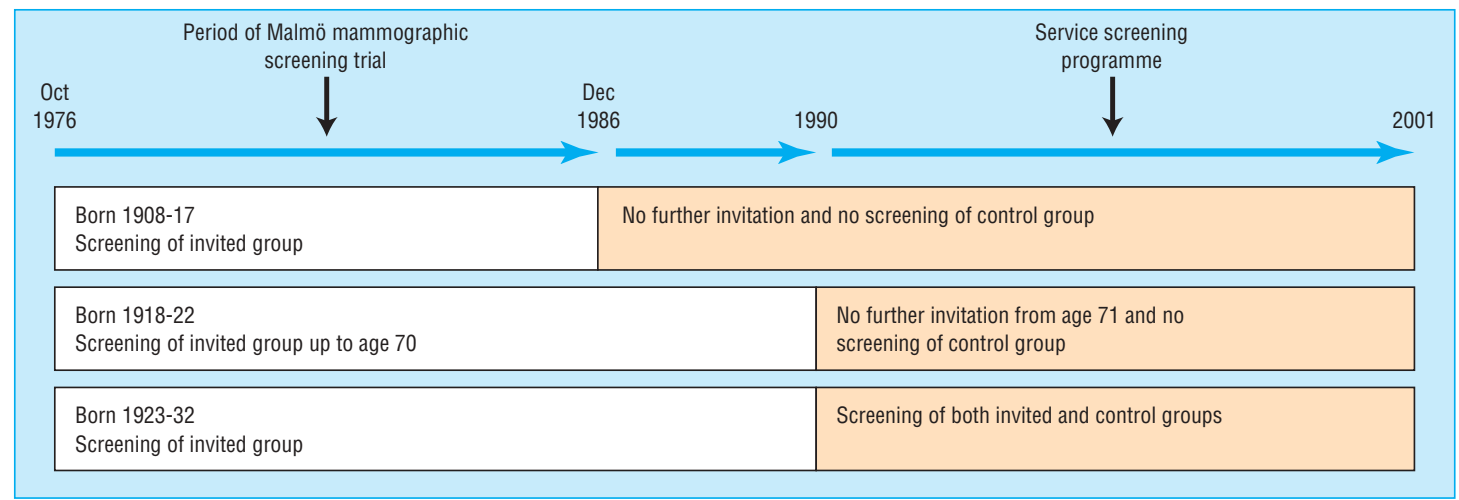

Fig 1 Schematic overview of periods 1 (unshaded) and 2 from start of Malmö mammographic screening trial to follow-up 15 years after trial ended 
Table 1 Incidence and relative rates for breast cancer according to age and trial group in Malmö mammographic screening trial from randomisation until end of follow-up (31 December 2001)

\begin{tabular}{|c|c|c|c|c|c|c|c|c|c|}
\hline \multirow[b]{2}{*}{$\begin{array}{l}\text { Birth } \\
\text { cohort }\end{array}$} & \multirow[b]{2}{*}{$\begin{array}{c}\text { Age at } \\
\text { randomisation }\end{array}$} & \multicolumn{3}{|c|}{ Invited group } & \multicolumn{3}{|c|}{ Control group } & \multicolumn{2}{|c|}{ Relative risk $(95 \% \mathrm{Cl})$ invited $v$ controls } \\
\hline & & $\begin{array}{l}\text { No of cases of } \\
\text { breast cancer (No } \\
\text { invasive) }\end{array}$ & $\begin{array}{l}\text { Person } \\
\text { years }\end{array}$ & $\begin{array}{c}\text { Incidence per } \\
1000 \text { person } \\
\text { years* }\end{array}$ & $\begin{array}{l}\text { No of cases of } \\
\text { breast cancer } \\
\text { (No invasive) }\end{array}$ & $\begin{array}{l}\text { Person } \\
\text { years }\end{array}$ & $\begin{array}{c}\text { Incidence per } \\
1000 \text { person } \\
\text { years* }\end{array}$ & All breast cancers $\dagger$ & $\begin{array}{l}\text { Invasive breast } \\
\text { cancer }\end{array}$ \\
\hline $1908-32$ & 45 to 69 (all) & $1320(1200)$ & 426812 & 3.09 & $1205(1116)$ & 429033 & 2.81 & 1.10 (1.01 to 1.18$)$ & 1.07 (0.99 to 1.17 \\
\hline $1908-22$ & 55 to 69 & $780(719)$ & 251376 & 3.10 & $698(662)$ & 250787 & 2.78 & 1.10 (0.99 to 1.22$)$ & $1.07(0.96$ to 1.18 \\
\hline $1923-32$ & 45 to 54 & 540 (481) & 175436 & 3.08 & 507 (454) & 178246 & 2.84 & 1.08 (0.96 to 1.22$)$ & 1.08 (0.95 to 1.23 \\
\hline
\end{tabular}

*All breast cancers.

†ln situ and invasive.

women aged 55-69 at randomisation, whose control groups were never invited for screening, a 32\% higher incidence was seen in period 1 followed by an $8 \%$ lower rate in the invited than in the control group in period 2.

After exclusion of the first two screening rounds in period 1, the excess incidence of all breast cancers was reduced. Relative rates were 1.12 (0.99 to 1.27$)$ in the total cohort, 1.19 (1.00 to $1.40)$ in women aged 55-69 at randomisation, and 1.04 (0.86 to 1.25 ) in women aged $45-54$ at randomisation.

\section{Causes of death}

During follow-up 9279 deaths occurred in the invited group and 9514 in the control group. Among 584 deaths in women in the invited group with breast cancer $212(36.3 \%)$ were due to breast cancer compared with 274 of $588(46.6 \%)$ in the control group.

\section{Discussion}

On the basis of direct observations we found a $10 \%$ rate of overdiagnosis of breast cancer 15 years after the end of the Malmö mammographic screening trial. This trial was population based, randomisation was by individual, and the trial time was longer and more screening rounds were completed than in any other trial of screening for breast cancer. The randomised design was maintained for almost five years after the trial had ended. The control groups of the 15 oldest birth cohorts were never invited for screening.

Earlier studies on over-diagnosis (cases that would never have come to clinical attention without screening) were mostly carried out in the setting of a screening service and included estimates and statistical modelling that should be taken into account when comparing the results. A Norwegian study showed $50 \%$ over-diagnosis, but follow-up was insufficient. ${ }^{6}$ A recent Swedish study of increasing incidence of invasive breast cancer after the introduction of screening showed 21-54\% excess incidence depending on age. ${ }^{7}$ The authors did point out the possibility that the observed incidence could be caused by increased use of hormone replacement therapy or by changes in childbirth alone or in combination with screening. Evaluation of the Nijmegen programme in 1989, which used geographically distinct controls, showed an excess of $11 \%$ of breast cancer over a 12 year period, which is in line with our results. ${ }^{10} \mathrm{~A}$ recent study using statistical modelling, based on two trials (Swedish two-county and Gothenburg trials) suggests a much lower rate of over-diagnosis $(1 \%){ }^{11}$

One study showed that a relatively large proportion of ductal cancer in situ lesions detected at prevalent and incident screens would be progressive if left untreated. They concluded that overdiagnosis of this type of cancer was a minor problem due owing to the low detection rate. ${ }^{12}$ This would be in line with our results where excess incidence was in the main not generated by in situ cancer, which was the case in an Italian study. ${ }^{4}$ Some studies did not include ductal cancer in situ in the main analyses, ${ }^{710}$ whereas others carried out analyses both with and without this type of cancer. ${ }^{68}$ We believe that in situ cancers should be included in analyses.

The main explanation for the excess number of cases in the invited group is the lead time of cases detected by screening. Owing to death due to intercurrent disease some of the cases would never have come to clinical attention. In addition some cases may have been non-progressive and therefore would never become noticeable in the absence of screening. This means that a long follow-up is necessary to estimate the magnitude of overdiagnosis and that analysis after only a few screening rounds is insufficient. In our study about $60 \%$ of the women aged 55-69 years at randomisation had died by the end of follow-up.

\section{Age at randomisation}

55-69 years

When screening ends a reduction in breast cancer incidence is expected in the former invited groups. Among women aged 55-69 at randomisation, however, we found only a modest reduction during period 2 . The lead time has been shown to be longer in older women than in younger women. ${ }^{13}{ }^{14}$ This fact together with an age dependent increasing general death rate

Table 2 Incidence and relative rates of all breast cancers by age at randomisation and trial group in periods 1 and 2

\begin{tabular}{|c|c|c|c|c|c|c|c|c|}
\hline \multirow[b]{2}{*}{$\begin{array}{l}\text { Period and birth } \\
\text { cohort }\end{array}$} & \multirow[b]{2}{*}{$\begin{array}{c}\text { Age at } \\
\text { randomisation }\end{array}$} & \multicolumn{3}{|c|}{ Invited group } & \multicolumn{3}{|c|}{ Control group } & \multirow[b]{2}{*}{$\begin{array}{l}\text { Relative rate }(95 \% \mathrm{Cl}) \text { invited } \\
v \text { controls for all breast cancers } \\
\text { (in situ and invasive) }\end{array}$} \\
\hline & & $\begin{array}{l}\text { No of breast } \\
\text { cancer cases }\end{array}$ & $\begin{array}{c}\text { Person } \\
\text { years }\end{array}$ & $\begin{array}{c}\text { Incidence } \\
\& \# 10 ; \text { per } 1000 \\
\text { person years }\end{array}$ & $\begin{array}{l}\text { No of breast } \\
\text { cancer cases }\end{array}$ & Person years & $\begin{array}{l}\text { Incidence per } \\
1000 \text { person } \\
\text { years }\end{array}$ & \\
\hline \multicolumn{9}{|l|}{ Period 1: } \\
\hline 1908 to 32 & 45 to 69 (all) & 741 & 236958 & 3.13 & 591 & 238831 & 2.47 & 1.24 (1.12 to 1.39$)$ \\
\hline 1908 to 22 & 55 to 69 & 438 & 127742 & 3.43 & 324 & 127893 & 2.53 & 1.32 (1.14 to 1.53$)$ \\
\hline 1923 to 32 & 45 to 54 & 303 & 109216 & 2.77 & 267 & 110938 & 2.41 & $1.16(0.98$ to 1.36$)$ \\
\hline \multicolumn{9}{|l|}{ Period 2: } \\
\hline 1908 to 32 & 45 to 69 (all) & 579 & 183332 & 3.16 & 614 & 185108 & 3.32 & 0.95 (0.85 to 1.06$)$ \\
\hline 1908 to 22 & 55 to 69 & 342 & 118509 & 2.89 & 374 & 119110 & 3.14 & $0.92(0.79$ to 1.06$)$ \\
\hline 1923 to 32 & 45 to 54 & 237 & 64823 & 3.66 & 240 & 65998 & 3.64 & $1.01(0.84$ to 1.20$)$ \\
\hline
\end{tabular}

Only invited group was screened in period 1. In period 2 women born during 1908-22 were not screened but screening took place of former invited and control groups in women born 1923-32. 


\section{Research}

could explain the remaining substantial over-diagnosis at the end of the period of observation. Møller et al recently showed a $32 \%$ reduction in breast cancer incidence in Swedish women past the upper age limit of their screening programme. ${ }^{15}$ The women in our study were older when screening stopped, which may explain the difference.

\section{5-54 years}

No definite conclusions can be drawn for over-diagnosis in the younger cohorts as the control groups were later screened. This resulted in an equalisation of the cumulative rate at first but at the end a not statistically significant $8 \%$ higher incidence in the former invited group. In other trials almost no excess incidence was shown when the control group was invited, which is to be interpreted as similar rates of over-diagnosis in both groups. ${ }^{8}$

\section{Exclusion of prevalent cases}

We analysed the extent of excess incidence after exclusion of prevalent cases (the first two screening rounds) and found a remaining, but reduced, excess incidence. This shows that the excess incidence is not just related to prevalent cases in a population exposed to screening. Two screening rounds correspond to four years, and the average lead time has been estimated to be two to four years depending on age. ${ }^{13}{ }^{14}$ Most of the prevalent cases in the invited group and their corresponding cases in the control group should therefore have been accounted for. An increasing incidence at incident screens could be due to higher sensitivity of the screening procedure, which in turn may be due to improvements in mammography, increased knowledge among radiologists, or changes in the criteria for recall.

\section{Factors influencing over-diagnosis}

Attendance rates for screening decrease with age, as shown in both the Malmö mammographic screening trial and in the subsequent service screening programme. ${ }^{16}{ }^{17}$ On the other hand, women who had been screened in the Malmö trial were more likely to attend the service screening programme ${ }^{17}$ and probably also to undergo mammography after screening had ended. Furthermore, mammography of asymptomatic women outside the trial in the control groups may lead to underestimation of overdiagnosis.

It is widely agreed that screening using mammography can reduce mortality from breast cancer. ${ }^{18-24}$ The rate of overdiagnosis is another issue to be considered in the ongoing discussion about clinical and public health implications of breast cancer screening.

\section{What is already known on this topic}

Rates of over-diagnosis in screening for breast cancer have been estimated at $5 \%$ to $50 \%$

Evidence from randomised controlled trials is lacking

What this study adds

Over-diagnosis of breast cancer was $10 \%$ in women randomised to screening at age 55-69 years compared with an unscreened control group

Calculations are based on direct observations of follow-up 15 years after the end of a randomised controlled trial
Contributors: SZ, IA, LJ, JM, and JPG designed and planned the study. SZ did the statistical analyses and wrote the paper. All authors contributed to the drafting of the paper and the final version. SZ is guarantor.

Funding: None.

Competing interests: None declared.

Ethical approval: Ethical committee of Lund University.

1 Baines CJ. Are there downsides to mammography screening? Breast J 2005;11:S7-10. Duffy SW. Some current issues in breast Day NE Overdiagnosis and breast cancer screening. Breas Cancer Res 2005;7:928-9.

4 Paci E, Warwick J, Falini P, Duffy SW. Overdiagnosis in screening: is the increase in breast cancer incidence rates a cause for concern? J Med Screen 2004;11:23-7.

5 Olsen AH, Jensen A, Njor SH, Villadsen E, Schwartz W, Vejborg I, et al. Breast cance incidence after the start of mammography screening in Denmark. Br J Cancer 2003;88:362-5.

6 Zahl PH, Strand BH, Maehlen J. Incidence of breast cancer in Norway and Sweden during introduction of nationwide screening: prospective cohort study. BMJ 2004;328:921-4.

7 Jonsson H, Johansson R, Lenner P. Increased incidence of invasive breast cancer after the introduction of service screening with mammography in Sweden. Int I Cancer 2005;117:842-7

8 Moss S. Overdiagnosis and overtreatment of breast cancer: overdiagnosis in rand graphic screening and mortality from breast cancer: the Malmö mammographic screening trial. BMJ 1988;297:943-8.

10 Peeters PH, Verbeek AL, Straatman H, Holland R, Hendriks JH, Mravunac M, et al. Evaluation of overdiagnosis of breast cancer in screening with mammography: results of the Nijmegen programme. Int J Epidemiol 1989;18:295-9.

11 Duffy SW, Agbaje O, Tabár L, Vitak B, Bjurstam N, Bjorneld L, et al. Overdiagnosis and overtreatment of breast cancer: estimates of overdiagnosis from two trials of mammographic screening for breast cancer. Breast Cancer Res 2005;7:258-65.

12 Yen MF, Tabár L, Vitak B, Smith RA, Chen HH, Duffy SW. Quantifying the potential problem of overdiagnosis of ductal carcinoma in situ in breast cancer screening. Eur J Cancer 2003:39:1746-54

13 Shapiro S, Goldberg JD, Hutchison GB. Lead time in breast cancer detection and implications for periodicity of screening. Am J Epidemiol 1974;100:357-66.

14 Moskowitz M. Breast cancer: age-specific growth rates and screening strategies. Radiology 1986;161:37-41.

15 Møller B, Weedon-Fekjaer H, Hakulinen T, Tryggvadottir L, Storm HH, Talbäck M, et al. The influence of mammographic screening on national trends in breast cancer incidence. Eur J Cancer Prev 2005;14:117-28.

16 Matson S, Andersson I, Berglund G, Janzon L, Manjer J. Non-attendance in mammographic screening. A study of intra-urban differences from the city of Malmö in Sweden 1990-94. Cancer Detect Prev 2001;25:132-7.

17 Zackrisson S, Andersson I, Manjer J, Janzon L. Non-attendance in breast cancer screening is associated with unfavourable socio-economic circumstances and advanced carcinoma. Int J Cancer 2004:108:754-60.

18 Nyström L, Rutqvist LE, Wall S, Lindgren A, Lindqvist M, Rydén S, et al. Breast cancer screening with mammography: overview of Swedish randomised trials. Lancet 1993:341:973-8.

19 Nyström L, Andersson I, Bjurstam N, Frisell J, Nordenskjöld B, Rutqvist LE. Long-term effects of mammography screening: updated overview of the Swedish randomised trials. Lancet 2002;359:909-19.

20 Tabár L, Fagerberg CJ, Gad A, Baldetorp L, Holmberg LH, Gröntoft O, et al. Reduction in mortality from breast cancer after mass screening with mammography. Randomised trial from the Breast Cancer Screening Working Group of the Swedish National Board of Health and Welfare. Lancet 1985;1:829-32.

21 Jonsson H, Nyström L, Törnberg S, Lenner P. Service screening with mammography of women aged 50-69 years in Sweden: effects on mortality from breast cancer. J Med Screen 2001;8:152-60.

22 Duffy SW, Tabar L, Chen HH, Holmqvist M, Yen MF, Abdsalah S, et al. The impact of organized mammography service screening on breast carcinoma mortality in seven Swedish counties. Cancer 2002;95:458-69.

23 Berry DA, Cronin KA, Plevritis SK, Fryback DG, Clarke L, Zelen M, et al. Effect of screening and adjuvant therapy on mortality from breast cancer. $N$ Engl $J$ Med 2005;353:1784-92.

24 International Agency for Research on Cancer. IARC handbooks of cancer prevention. Breast cancer screening. Lyon, France: IARC Press, 2002.

(Accepted 27 January 2006)

doi $10.1136 /$ bmj.38764.572569.7C

Department of Clinical Sciences in Malmö, Epidemiological Research Group, Lund University, Malmö University Hospital, SE-205 02, Malmö, Sweden

Sophia Zackrisson doctor

Lars Janzon professor

Jonas Manjer associate professor

Medical Radiology, Malmö University Hospital

Ingvar Andersson associate professor

Department of Surgery, Aarhus University Hospital, DK 8000 Århus C, Denmark Jens Peter Garne associate professor

Correspondence to: S Zackrisson sophia.zackrisson@med.lu.se 